\title{
Revision and phylogenetics of the genus Paraulax Kieffer (Hymenoptera, Cynipidae) with biological notes and description of a new tribe, a new genus, and five new species
}

\author{
JOSÉ LUIS NIEVES-ALDREY ${ }^{1,5}$, JOHAN LILJEBLAD ${ }^{2}$, MARÍA HERNÁNDEZ NIEVES ${ }^{1}$, \\ AUDREY GREZ ${ }^{3}$ \& JOHAN A. A. NYLANDER ${ }^{4}$ \\ ${ }^{1}$ Museo Nacional de Ciencias Naturales (CSIC), Departamento de Biodiversidad y Biología Evolutiva, C/ José Gutiérrez Abascal 2, \\ ES-28006 Madrid, Spain \\ ${ }^{2}$ Swedish Species Information Centre, P.O. Box 7007, SE-750 07, Uppsala, Sweden. E-mail: cynips@gmail.com \\ ${ }^{3}$ Departamento de Ciencias Biológicas Animales, Facultad Ciencias Veterinarias y Pecuarias, Universidad de Chile, Avda. Santa \\ Rosa 11735, La Pintana, Santiago, Chile.E-mail: agrez@uchile.cl \\ ${ }^{4}$ Department of Botany, Stockholm University, SE-106 91 Stockholm, Sweden. E-mail: johan.nylander@botan.su.se \\ ${ }^{5}$ Corresponding author. E-mail: aldrey@mncn.csic.es
}

\section{Table of contents}

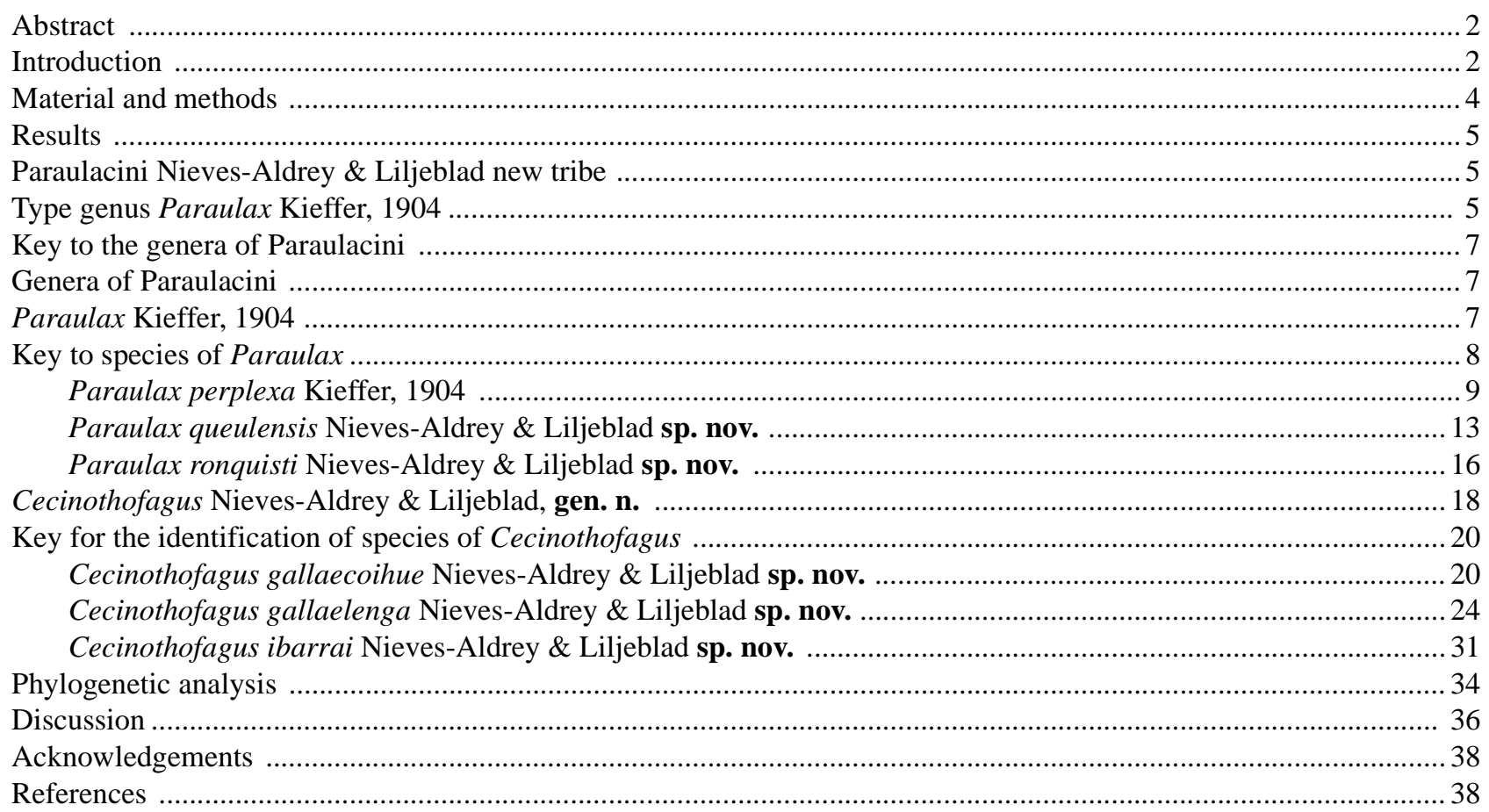




\begin{abstract}
The gall wasp genus Paraulax (Hymenoptera, Cynipidae) associated with southern beeches (Nothofagus (Nothofagaceae)) from South America is revised. The genus Paraulax and its type species, P. perplexa, are redescribed and a neotype is designated. Two additional species of Paraulax are described as new: P. queulensis and P. ronquisti. After having been first tentatively placed in the Cynipini and later transferred to the Pediaspidini, this genus is here placed in the newly erected tribe Paraulacini, together with the herein described genus Cecinothofagus and the three species that are described as new: $C$. gallaecoihue, $C$. gallaelenga and $C$. ibarrai.

The biology of the members of this new tribe is discussed. Contrary to a prior hypothesis that postulated Paraulax (sensu lato) to be true gall-inducers, as most cynipids, evidence here shows that the three species of the new genus Cecinothofagus are instead parasitoids or lethal inquilines inhabiting galls induced by species of Aditrochus (Pteromalidae) on Nothofagus. The biology of the Paraulax species is unknown but since they too are associated with Nothofagus forests their biology is likely associated with the pteromalid gall community. We describe host plant associations as well as the morphology and phenology of the host gall.

A phylogenetic reconstruction of the Paraulacini and selected Cynipidae taxa, based on 28S and COI, is performed. Both markers indicate the Paraulacini to be monophyletic and support a sister group relationship with the Pediaspidini. Results from $28 \mathrm{~S}$ are congruent with both the morphological evidence and the proposed classification.
\end{abstract}

Key words: Cynipidae, evolution, gall wasp, inquiline, life history, South America, Paraulax, Cecinothofagus, Aditrochus, Nothofagus

\title{
Introduction
}

The Gall wasps (Cynipidae) are a species-rich group of herbivorous insects that either induce galls on plants or develop as obligate inhabitants (termed inquilines) in the galls induced by other insects. In this second case, the inquilines usually inhabit the gall of another cynipid, a relation that has been called agastoparasitism (Ronquist 1994). Gall inducing cynipids are separated into five tribes, each associated with a different set of plant hosts - the Cynipini gall plants of the family Fagaceae, the Pediaspidini, according more recent classsification (Liljeblad et al. 2008), gall southern beeches (Nothofagus) and maples (Acer), the Diplolepidini gall plants of the genus Rosa (Rosaceae), the Eschatocerini gall Acacia and Prosopis (Fabaceae), while the Aylacini gall a range of herbaceous plants (Ronquist 1999; Nieves-Aldrey 2001; Liu \& Ronquist 2006). The inquiline gall wasps are currently classified as members of a single tribe, the Synergini, although molecular evidence suggests that the group is not monophyletic and group in at least two separate clades, one associated to galls on Fagaceae and Anacardiaceae, and other in galls on Rosaceae (Nylander et al. 2004; Van Noort et al. 2007). The largest cynipid radiation on a specific host plant group is represented by the oak gall wasps (Cynipini) with about 1000 described species all in the Northern Hemisphere. In this association in particular, like cynipids in general, they appear to have mantained a high degree of host plant specificity (Ronquist \& Liljeblad 2001; Liljeblad et al. 2008; Stone et al. 2002, 2009).

The Cynipidae are predominately a Northern Hemisphere group, and most of the approximately 1300 described species are Holarctic (Nieves-Aldrey 2001; Csoka et al. 2005; Liu \& Ronquist 2006; Liljeblad et al. 2008). The exceptions are three genera: Paraulax Kieffer and Eschatocerus Mayr that are native of temperate South America (Díaz 1981; Liu \& Ronquist 2006), and the South Africa endemic Rhoophilus Mayr (van Noort et al. 2007). Another cynipid of uncertain taxonomic status, linked to galls on Scolopia mundii (Eckl. \& Zeyh.) Warb. (Flacourtiaceae) is known from eastern South Africa, but remains undescribed (Liljeblad et al. 2008; Liljeblad, Nieves-Aldrey \& Melika in prep.).

Paraulax is a poorly known and interesting genus that has rarely been collected, and thus is virtually absent from entomological collections. Furthermore, the location of the types of $P$. perplexa, the only described species until now, is unknown and presumed to be lost (Weld 1952). There is no host record for $P$. perplexa and references to the biology of this species have been indirect or uncertain. 